\title{
Use of sugammadex in patients with neuromuscular disorders: a systematic review of case reports
}

\author{
Usha Gurunathan $^{1,2^{*}}$, Shakeel Meeran Kunju ${ }^{1,2}$ and Lisa May Lin Stanton ${ }^{1}$
}

\begin{abstract}
Background: Sugammadex is a modified gamma-cyclodextrin that acts by selectively encapsulating free aminosteroidal neuromuscular relaxants. Several case reports have been published on the use of sugammadex in patients with neuromuscular disorders that include neuromuscular junction diseases, myopathies, neuropathies, and motor neurone disorders. The primary aim of this review is to systematically review the evidence on the use of sugammadex in patients with this heterogeneous group of diseases and provide recommendations for clinical practice.

Methods: A systematic electronic search of Medline, Embase and CINAHL databases was done until June 2019, to identify case reports describing the use of sugammadex in adult surgical patients with neuromuscular disorders.

Results: Of the 578 records identified through database searches, 43 articles were finally included for the systematic review. Of these, 17 reports were on patients with myopathy, 15 reports on myasthenia gravis, 9 reports on motor neuron diseases and 2 reports on neuropathies.

Conclusions: Majority of the articles reviewed report successful use of sugammadex to reverse steroidal muscle relaxants, especially rocuronium, in patients with neuromuscular diseases. However, with sugammadex, unpredictability in response and uncertainty regarding optimum dose still remain issues. Quantitative neuromuscular monitoring to ensure complete reversal and adequate postoperative monitoring is strongly recommended in these patients, despite the use of sugammadex.
\end{abstract}

Keywords: Sugammadex, Neuromuscular diseases, Rocuronium, Neuromuscular blockade, Reversal

\section{Background}

Neuromuscular disorders are a large heterogeneous group of diseases that are usually progressive and produce symptoms at widely differing age ranges with varying degrees of severity [1]. They can be classified into motor neuron diseases, neuropathies, neuromuscular junction disorders or myopathies depending on which section of neuromuscular system is affected [1] (Table 1). Epidemiological studies report an increase in the prevalence of neuromuscular disorders worldwide [2-4]. There have been several publications expressing concerns over the choice of muscle relaxants in patients with neuromuscular disorders presenting for

\footnotetext{
* Correspondence: usha.gurunathan@health.qld.gov.au

'Department of Anesthesia and Perfusion Services, The Prince Charles

Hospital, Rode Road, Chermside, Queensland 4032, Australia

${ }^{2}$ University of Queensland, Brisbane, Australia
}

surgery but perhaps, the reversal of the effects of muscle relaxants is a greater concern.

Sugammadex (Bridion ${ }^{\circ}$, Organon/Schering-Plough USA) a modified $\gamma$-cyclodextrin, acts by selectively encapsulating free molecules of amino steroidal neuromuscular relaxants such as vecuronium and rocuronium forming 1:1 inclusion complex in the plasma, thereby creating a concentration gradient resulting in the reduction of the relaxant available at the neuromuscular junction [5-7]. The complex is pharmacologically inert, is not affected by acid-base status or temperature [8] and produces no hemodynamic changes [6]. Thus, sugammadex has been found to have a good safety profile so far, compared with neostigmine [9].

Due to its rapid onset of action, sugammadex has enabled rocuronium to be used in difficult intubation scenarios, where traditionally suxamethonium has been

C The Author(s). 2019 Open Access This article is distributed under the terms of the Creative Commons Attribution 4.0 International License (http://creativecommons.org/licenses/by/4.0/), which permits unrestricted use, distribution, and 
Table 1 Classification of the neuromuscular disorders

\author{
1. Neuromuscular transmission disorders: Myasthenia Gravis, Lambert- \\ Eaton syndrome. \\ 2. Myopathies: Muscular dystrophies including myotonias- dystrophic \\ and non-dystrophic myotonias, poly- and dermatomyositis, metabolic \\ and mitochondrial myopathies. \\ 3. Neuropathies: Inflammatory polyneuropathy (Guillain - Barré \\ syndrome), hereditary and toxic polyneuropathy (Charcot-Marie-Tooth \\ disease, Fredreich's ataxia), multiple sclerosis \\ 4. Motor neuron diseases: Amyotrophic lateral sclerosis, spinal muscular \\ atrophy, spinal bulbar muscular atrophy
}

the relaxant of choice [10]. Sugammadex also permits the anesthesiologist to use high dose of rocuronium both for rapid sequence induction and intubation [11] as well as to ensure optimal surgical conditions, by enabling a complete motor recovery and reduced need for postoperative ventilatory support [12]. Moreover, the time taken by sugammadex to adequately reverse moderate to deep block has been found to be shorter than that for neostigmine [10]. Hence, the use of sugammadex is being increasingly reported in patients with neuromuscular disorders. However, synthesis of the evidence from these isolated case reports may provide a more meaningful guidance to the anesthesiologists with their management of such patients and to generate new research hypotheses.

The purpose of the following review is to evaluate the evidence supporting the use of sugammadex as a reversal agent in patients with neuromuscular disorders, in terms of its efficacy and dose requirements and to summarize various aspects that need to be considered during administration of this drug. A detailed review of neuromuscular diseases and their anesthetic considerations is outside the scope of this article.

\section{Methods}

A search was done by the reviewers (U.G and L.S) in Medline, Embase and CINAHL using the key Medical Subject Headings (MeSH) terms, "sugammadex", "neuromuscular diseases", "neuromuscular junction disorders", "myopathy", "neuropathy", "hereditary motor sensory neuropathy", "motor neuron disease", "neuromuscular transmission disorders", "Neuromuscular blocking" for studies including case reports on adult humans, and published in peer-reviewed journals, without any restriction on the year of publication. The last search was on 24 June 2019. Adult surgical patients with all variants of neuromuscular diseases who received sugammadex for reversal were eligible for inclusion. Paediatric case reports were excluded. Conference abstracts without full text availability and the articles that were not in English were excluded. Controlled trials on sugammadex, studies that did not use neuromuscular monitoring or did not report train-of-four ratio (TOF ratio) or count (TOF count) were excluded. Authors were not contacted for additional information. Duplicates were removed. Full texts of the articles from the relevant abstracts were reviewed. The reference list of the articles thus obtained was manually searched for any additional relevant article by L.S.

Two reviewers (U.G and S.K) independently screened the title and abstracts of all the articles from the literature search to select articles for full-text review with the inclusion and exclusion criteria. Any discrepancy was resolved by mutual consensus and discussion with the reviewer (L.S). Data were extracted by U. G and S. K into an excel sheet and included author, year, country, patient details, nature of disease, type of surgery, duration of surgery, anesthetic agents, neuromuscular blocking agent and its dose, neuromuscular monitor used, dose of sugammadex and its response and postoperative course. Details of the selection process are given in the Preferred Reporting Items for Systematic Reviews and MetaAnalyses (PRISMA) diagram (Fig. 1).

\section{Results}

The search identified 578 citations, 72 relevant abstracts were screened, from which 29 articles excluded, leaving 43 articles suitable for review (Fig. 1). There were 22 publications from Europe, 15 publications from Asia and five from Australia. The maximum number of reports $(n=17)$ concerned patients with myopathies, followed by patients with myasthenia gravis $(n=15)$. One Australian paper [13] reported two cases, of which one concerned a patient with myotonic dystrophy and the other about a patient with spinal muscular atrophy. For the sake of classification, it was considered as two different reports. Two reports were on patients with neuropathies and nine on motor neuron diseases.

\section{Discussion}

Respiratory involvement in neuromuscular disorders can range from a reduction in inspiratory and expiratory muscle strength resulting in alveolar hypoventilation, poor clearance of airway secretions to atelectasis and respiratory failure ${ }^{1}$. There may be coexisting mild to moderate bulbar dysfunction increasing risk of aspiration and obstructive and central sleep apnea [14]. Hence, muscle relaxants have been cautiously or even sparingly used in patients with neuromuscular disorders in order to avoid the need for postoperative ventilatory support. However, inadequate relaxation due to restricted use of muscle relaxants can compromise the success of some abdominal and gynecological procedures $[15,16]$. Use of suxamethonium in patients with neuromuscular disorders may risk

\footnotetext{
${ }^{1}$ Patients with neuromuscular disorders have a high risk of postoperative respiratory complications including respiratory failure.
} 
Citations identified through database searches ( $n=578$ ) [Embase: 483; Medline: 45; CINAHL: 30]

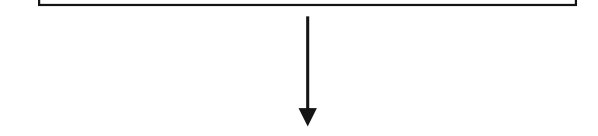

Records screened after duplicates removed $(n=72)$

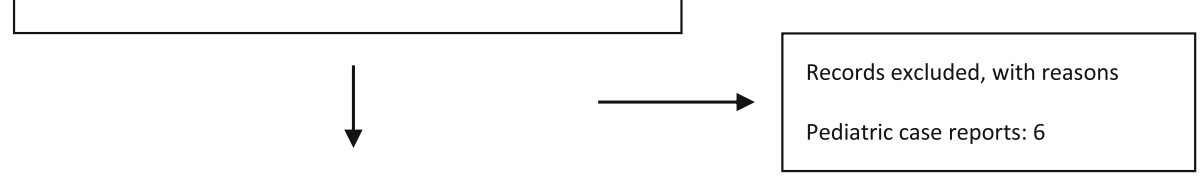

Full-text articles assessed for eligibility including additional articles from manual search of references $(n=66)$

Articles included in the systematic review $(n=43)$

Fig. 1 PRISMA flow diagram to illustrate the number of records selected for the systematic review and the reasons for exclusion

them with its undesirable side effects such as myalgia, malignant hyperthermia, decreased heart rate, masseter spasm, anaphylaxis, increased intracranial and intraocular pressure, hyperkalemia and prolongation of neuromuscular block in patients with congenital or acquired variations in plasma cholinesterase activity $[17,18]$. The response and duration of action of rocuronium can be variable and unpredictable in these patients [19]. Since patients with neuromuscular disorders may also have other associated conditions such as cardiomyopathy [20], systemic and pulmonary hypertension and arrhythmias, the conventional combination of reversal agents (neostigmine and anticholinergic drugs) may cause cardiac rhythm disturbances. Previous case reports have also described prolonged neuromuscular blockade similar to depolarizing block or a tonic response following the use of neostigmine in patients with neuromuscular disorders [21]. Other drawbacks of anticholinesterases such as neostigmine include relatively slow onset along with questionable reliability and predictability of reversal [22].
A recent Cochrane review concluded that sugammadex is faster, more efficient and safer than neostigmine in reversing moderate and deep paralysis $[23]^{2}$. Within our literature search, evidence was collected on the use of sugammadex in four main types of neuromuscular disorders:

\section{Neuromuscular transmission disorders (Table 2)}

Myasthenia gravis is a common autoimmune disorder that can manifest as muscle weakness that is either generalized or isolated to ocular/bulbar muscles. It may also be associated with autonomic instability. Dosing of muscle relaxants may pose challenges in patients with myasthenia gravis. They could be resistant to suxamethonium with up to twice-normal $\mathrm{ED}_{50}$ values, with increased risk of phase II blockade at higher doses [24]. In

\footnotetext{
${ }^{2}$ Sugammadex should be strongly considered as a safer and effective alternative to neostigmine in the reversal of steroidal muscle relaxants.
} 


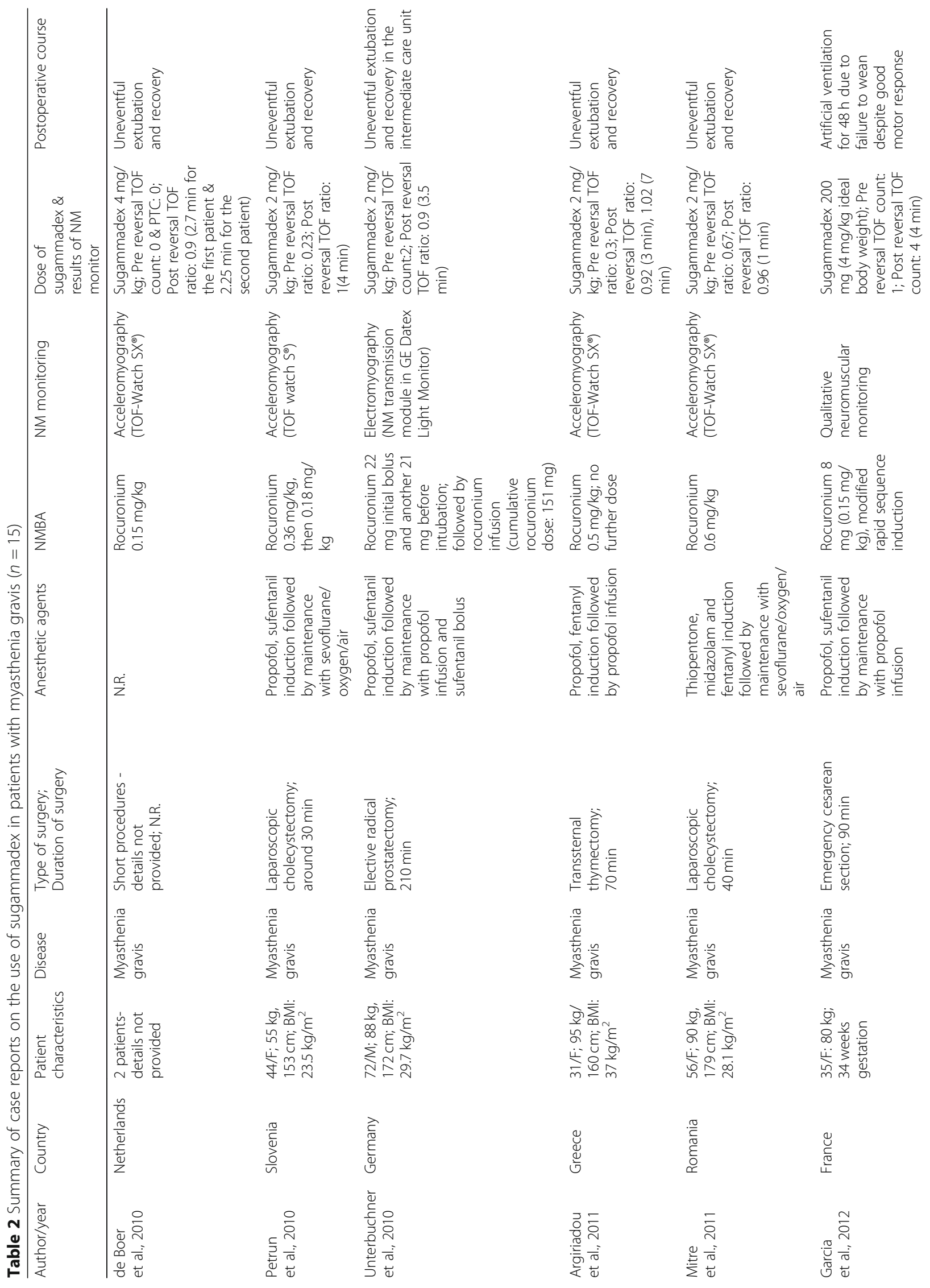




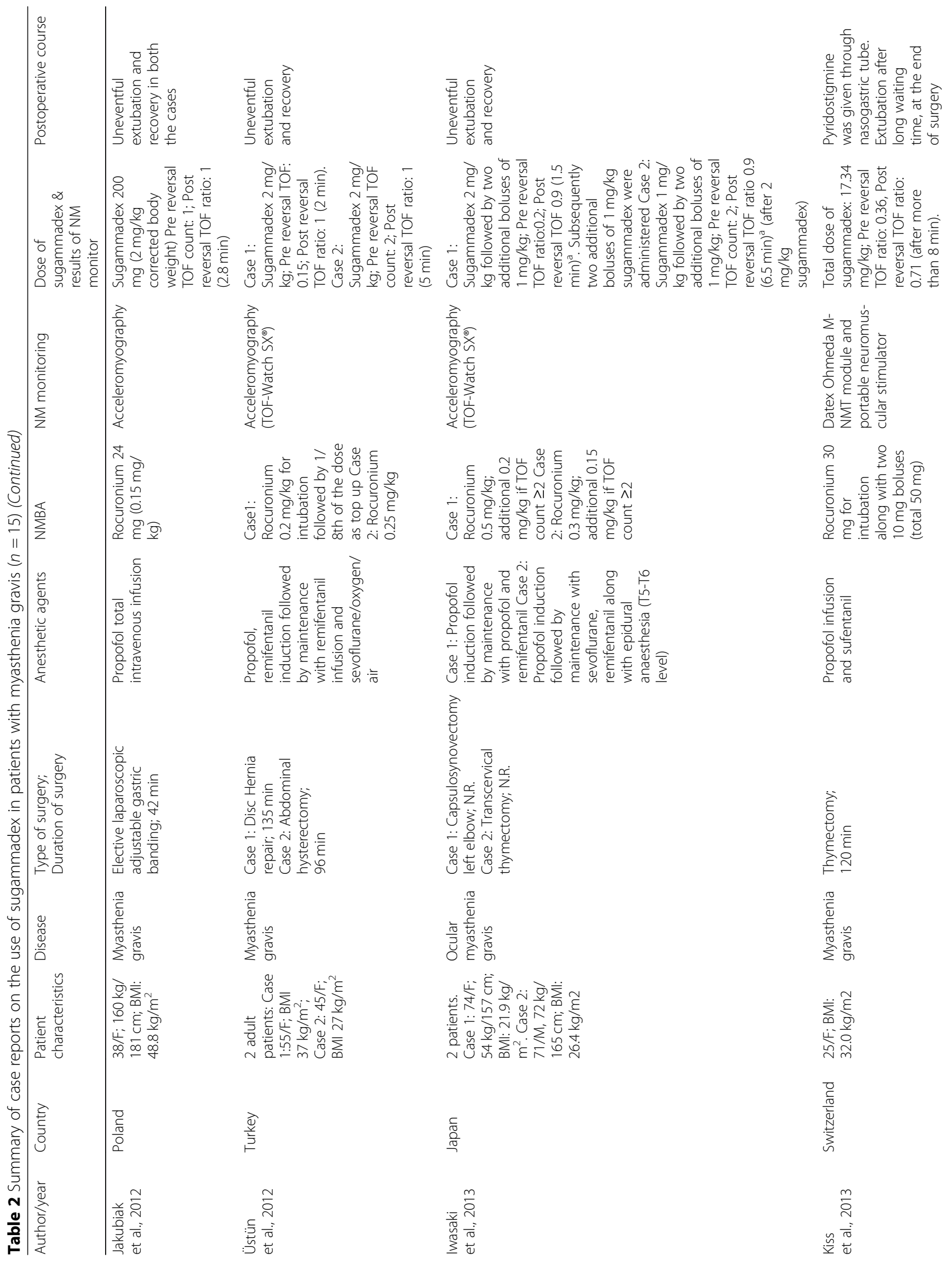




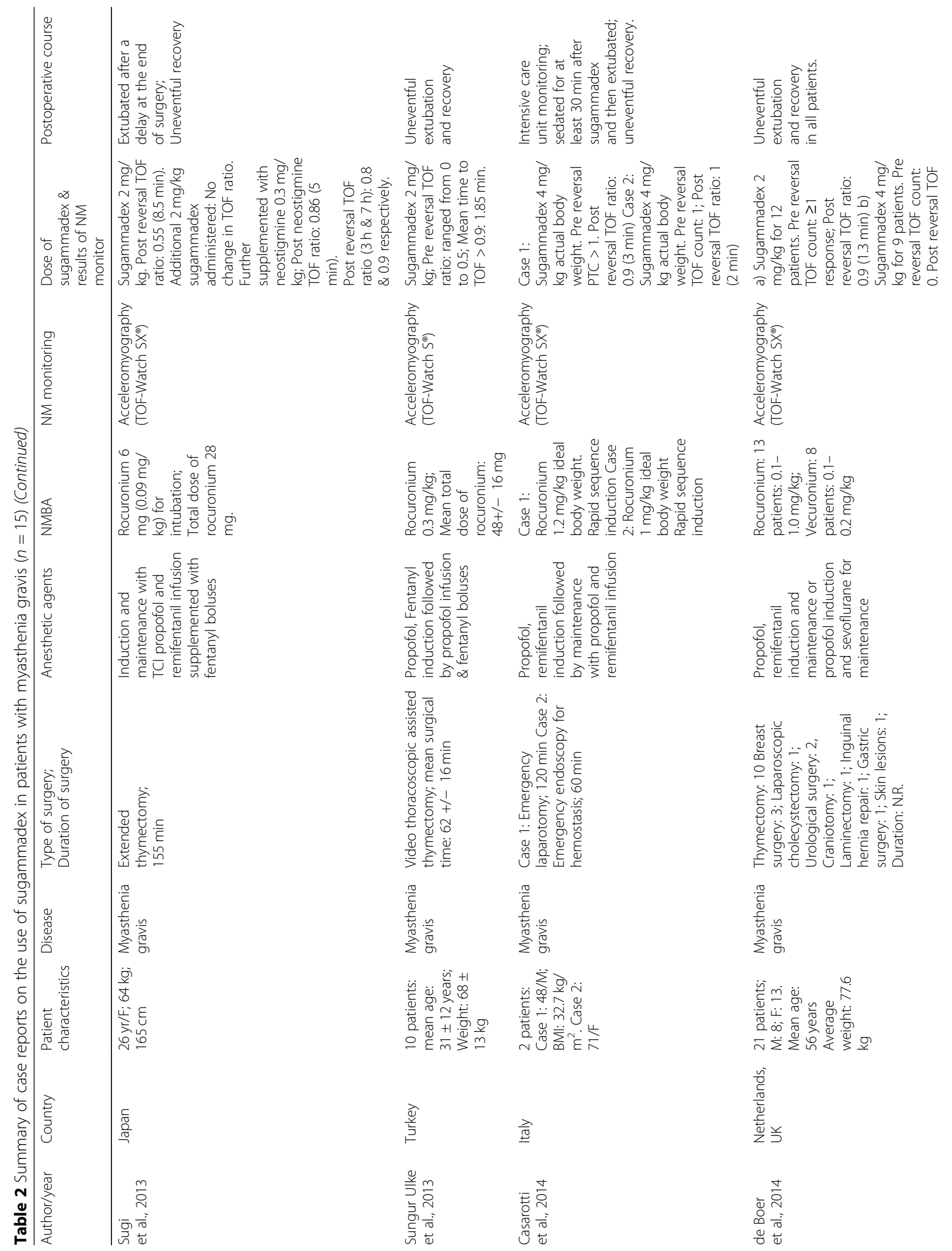


Gurunathan et al. BMC Anesthesiology

(2019) 19:213

Page 7 of 18

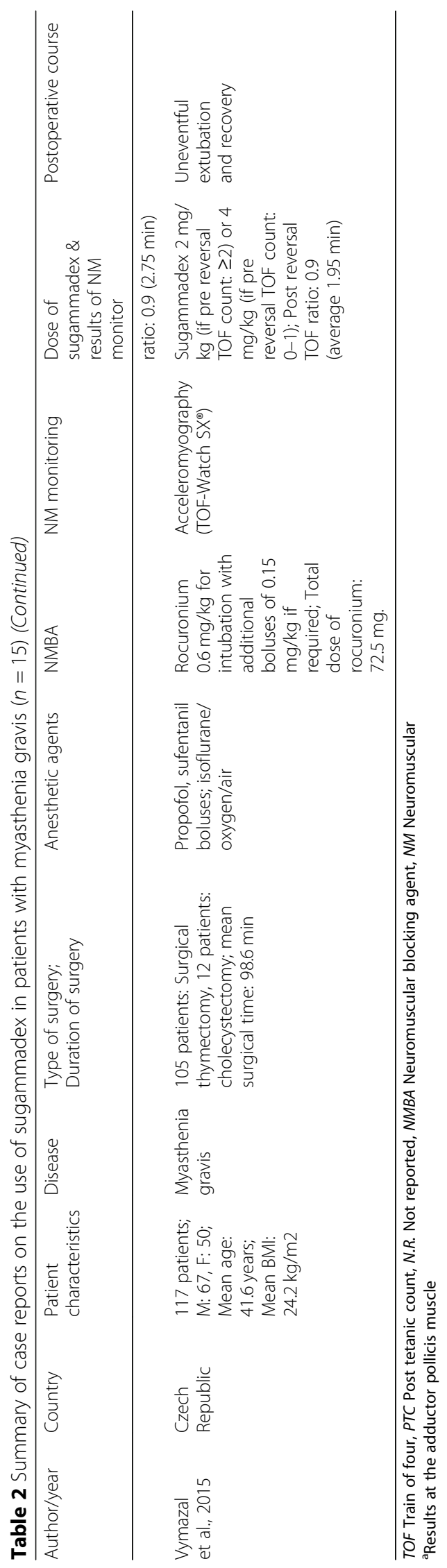


contrast, patients with myasthenia gravis are sensitive to non-depolarizing relaxants due to a decreased number of acetylcholine receptors and hence a dose reduction of these drugs has been recommended [25-27]. In the studies reviewed, the bolus intubating dose of rocuronium used in the patients with myasthenia gravis ranged from $0.09-1.2 \mathrm{mg} / \mathrm{kg}$. Factors such as the use of pyridostigmine and its dose may also impact on the effects and the duration of non-depolarising agents [28]. Moreover, since the acetylcholine esterase is already inhibited by pyridostigmine, reversing residual block with neostigmine may not be fully effective [24, 25, 27]. Use of sugammadex can provide fast and reliable recovery irrespective of preoperative continuation or cessation of pyridostigmine [29]. A large retrospective cohort study has shown a significant reduction in myasthenic crisis and hospital costs following surgery when sugammadex was used [30].

In the literature reviewed, the documented dosing of sugammadex was also found to vary between reports (Table 2). A dose of $2 \mathrm{mg} / \mathrm{kg}$ sugammadex has been noted to be sufficient even with a TOF count of 0 at the time of administration [31] whereas a dose of $4 \mathrm{mg} / \mathrm{kg}$ has been used by other authors [29, 32]. In the largest case series to date on the use of sugammadex in myasthenic patients, administration of sugammadex at 2 or 4 $\mathrm{mg} / \mathrm{kg}$ depending on a TOF count to $\geq 2$ or $0-1$ respectively, resulted in full reversal with a duration of less than 2 min on average [33]. ${ }^{3}$ However, as per the other reports in our review, complete reversal of relaxant effect occurred within around 3-4 min following sugammadex administration. Interestingly, four reports [32, 34-36] describe persistent residual paralysis in patients with myasthenia gravis even after administration of sugammadex. Kiss et al. [34] described the persistence of neuromuscular blockade in a patient with myasthenia gravis, resulting in the administration of a total dose more than $16 \mathrm{mg} / \mathrm{kg}$, in addition to administration of pyridostigmine via nasogastric tube. This was attributed to both redistribution of muscle relaxant and artifact from neuromuscular monitors. Surgery-induced exacerbation of myasthenia gravis has also been noted to result in residual paralysis despite a sugammadex dose of 4 $\mathrm{mg} / \mathrm{kg}[32,35]$.

In terms of monitoring the adequacy of reversal, motor recovery can occur later at the corrugator supercilii muscle (CSM) than at the adductor pollicis muscle (APM) in patients with ocular myasthenia

\footnotetext{
${ }^{3}$ Reduced dose of rocuronium has been used in these patients while the standard recommended dose of sugammadex has been successfully used to reverse muscle relaxants in the majority of the published case reports.
}

gravis as opposed to individuals without the disease $[37]{ }^{4}$ In addition, recovery of TOF ratio may be faster than that of first twitch (T1) height after sugammadex administration as observed by Iwasaki et al. in two patients with myasthenia gravis. ${ }^{4}$ While the TOF ratio at the APM returned to $90 \%$ within $1.5 \mathrm{~min}$ and $6.5 \mathrm{~min}$ in their two patients, T1 recovery took up to $12 \mathrm{~min}$ and $13 \mathrm{~min}$ respectively and required additional doses of sugammadex. ${ }^{4}$ Hence the authors recommended monitoring TOF ratio as well as the recovery of T1 height to baseline at both APM and CSM, in patients with myasthenia gravis [37]. However, recovery of TOF ratio was found to lag behind T1 recovery in the case reported by Sugi et al. [35]. ${ }^{4}$

\section{Myopathies (Table 3)}

Muscular dystrophies are a heterogenous group of progressive neuromuscular disorders resulting from genetic mutations that cause dystrophic changes in muscles. The most common varieties are Duchenne, Becker and myotonic dystrophies [38]. Patients suffer varying patterns of skeletal muscle weakness depending on the mutation, cardiac abnormalities including cardiomyopathies with or without conduction defects and are prone to pulmonary infection and failure. Myotonic dystrophy is also characterized by prolonged contraction of muscle with defective relaxation. Renal dysfunction may be a common complication in patients with myotonic dystrophy [39]. Patients with myotonic dystrophy tend to show myotonic responses to suxamethonium [40] and increased sensitivity to non-depolarising muscle relaxants [41]. Reactions to neostigmine can also be unpredictable $[21,41]$. None of these reactions were observed by Imison et al. in the retrospective study on myotonic dystrophy patients [42].

Ten reports discussed the use of sugammadex patients with myotonic dystrophy and two reports in patients with Becker and Duchenne muscular dystrophy [20, 43] (Table 3). The dose of rocuronium have been very variable with these studies. Reduced doses $(<0.6 \mathrm{mg} / \mathrm{kg})$ of rocuronium have been administered to aid intubation in majority of the cases in our review ${ }^{3}[13,20,43-49]$. With these cases, the reversal times to TOF ratio of 0.9 with $2 \mathrm{mg} / \mathrm{kg}$ sugammadex ranged from $2 \mathrm{~min}[20,45$, $46]$ to $5 \mathrm{~min}[13,44,48]$. However, two authors have

\footnotetext{
${ }^{4}$ Variations from normal recovery patterns of muscle strength following administration of reversal agent have been observed in patients with neuromuscular diseases. In myasthenia gravis especially in ocular myasthenia, both spontaneously and with administration of sugammadex, earlier recovery of TOF ratio versus first twitch height and earlier recovery at corrugator supercilii muscle versus adductor pollicis muscle were observed. Hence, monitoring TOF ratio as well as the recovery of first twitch height to baseline at both the muscles is recommended.
} 


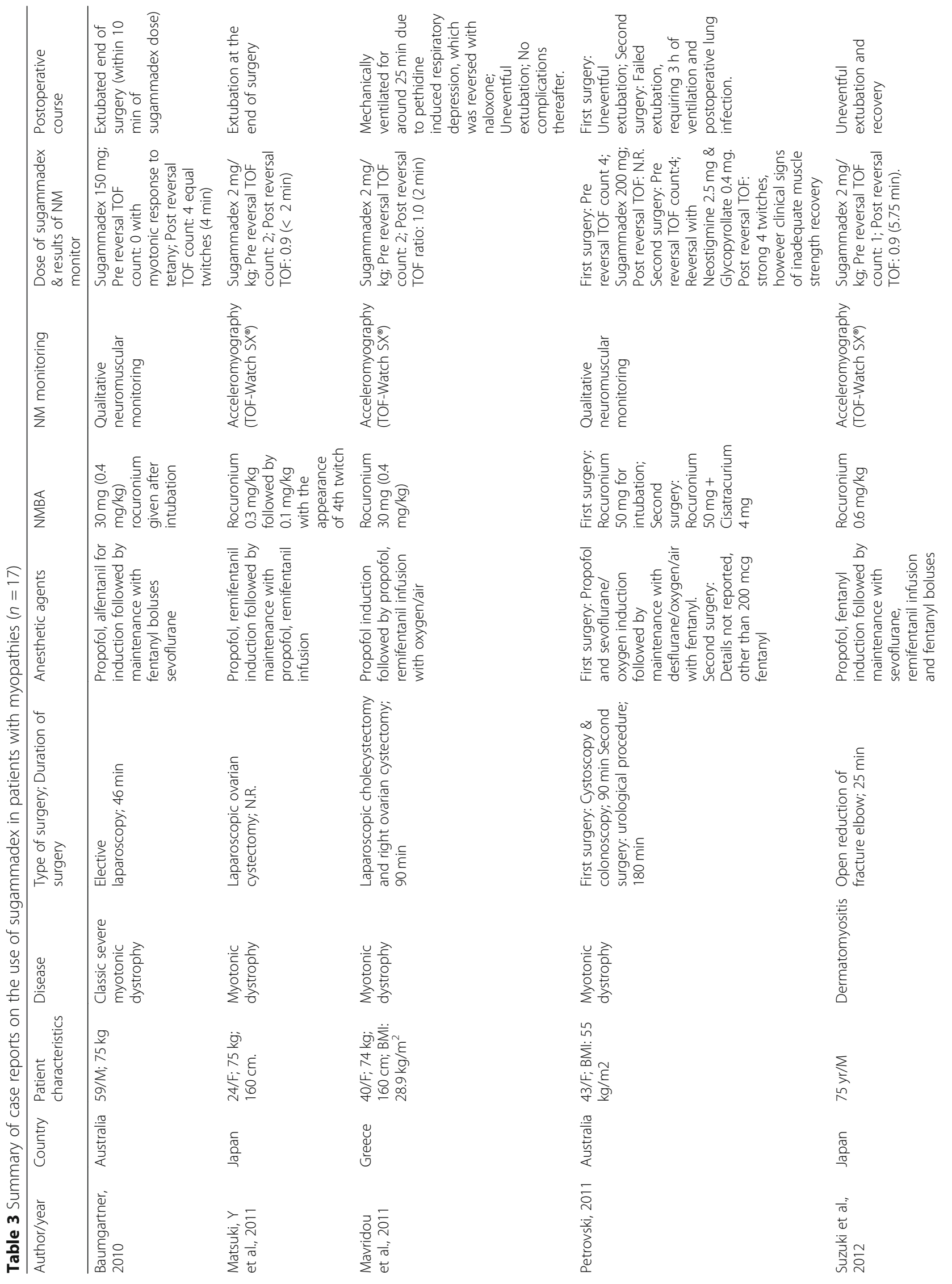




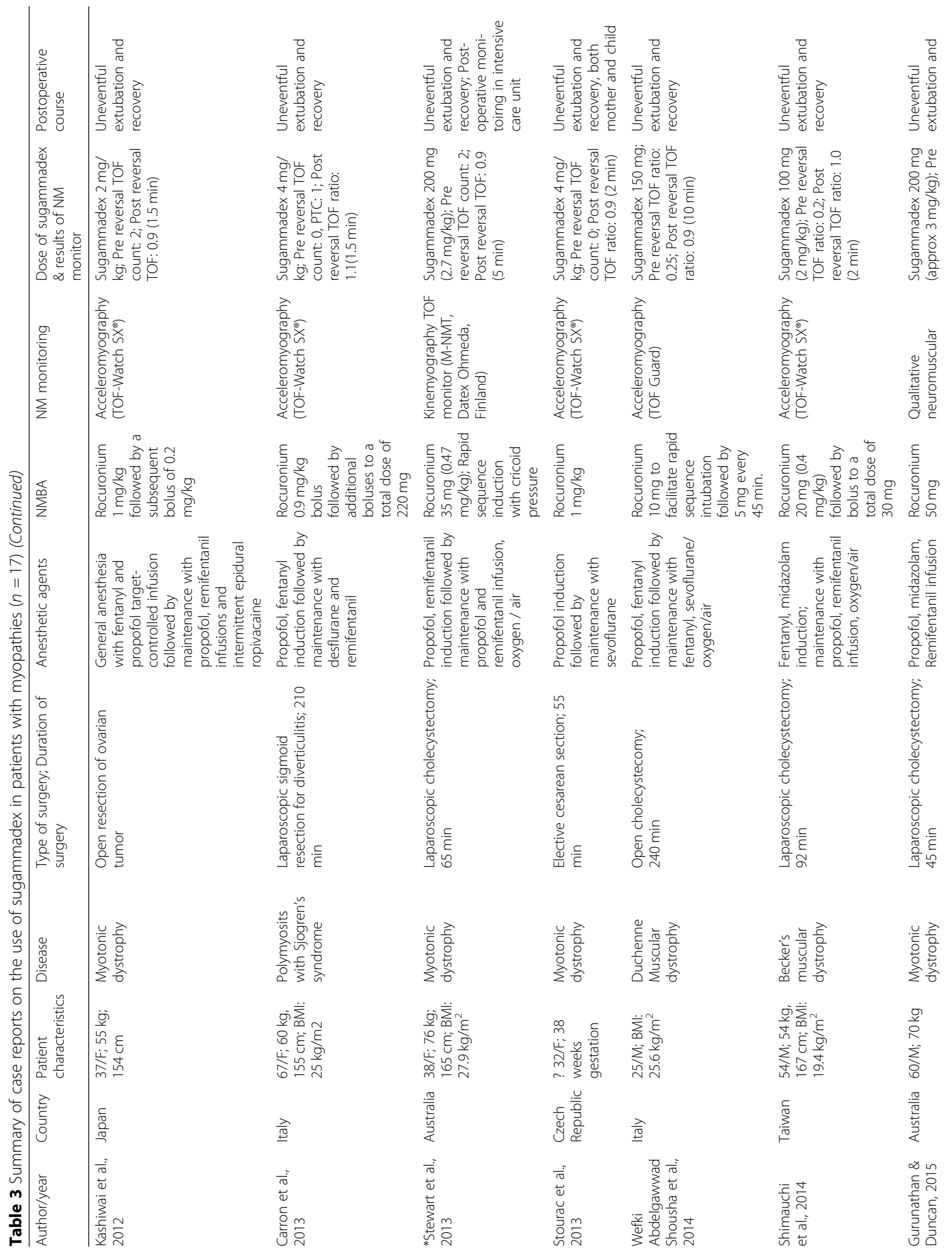




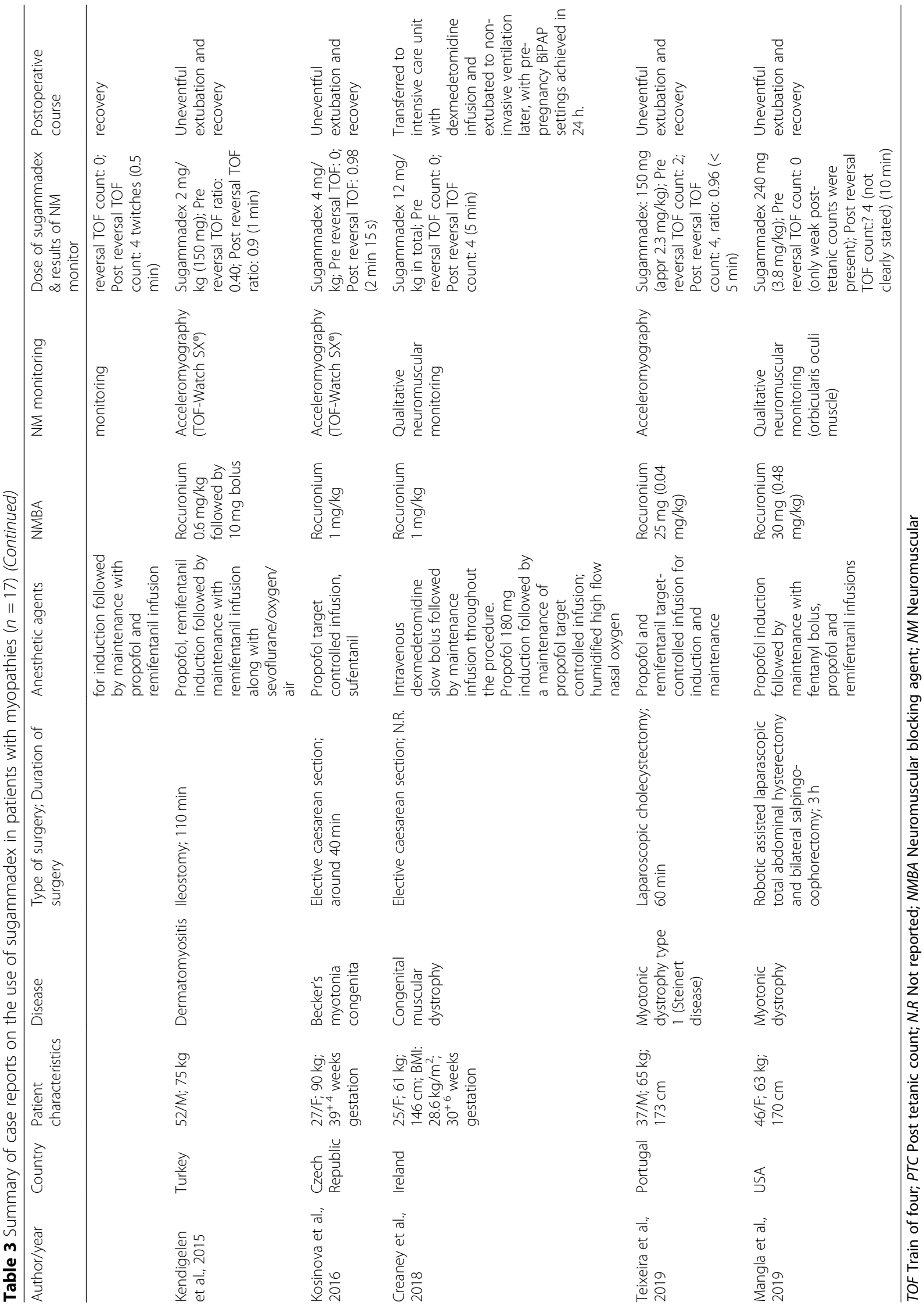


reported delayed neuromuscular recovery time of $10 \mathrm{~min}$ $[43,49]$, but no explanations were given. It is possible that slight underdosing of sugammadex could have contributed to the delay with Mangla et al. [49]. Three authors had used $1 \mathrm{mg} / \mathrm{kg}$ rocuronium to aid intubation, possibly related to their rapid sequence induction [50-52]. With all these cases, standard recommended doses of sugammadex were administered according to the TOF count and TOF ratio of 0.9 was reached within reasonable time $(<3 \mathrm{~min}){ }^{3}$ While response times to both rocuronium and sugammadex were not delayed, Stourac et al. observed prolonged duration of paralysis with rocuronium [51].

Polymyositis and dermatomyositis cause symmetrical weakness of proximal muscles due to an inflammatory process of the muscle itself with no impact on neuromuscular junction. However, two case reports on the use of sugammadex in patients with dermatomyositis, describe a delay in complete neuromuscular blockade (up to around $5 \mathrm{~min}$ ), which the authors attribute to vascular pathology associated with the disease process resulting in slow diffusion of rocuronium to neuromuscular junction [53, 54] (Table 3). Prolonged reversal time with sugammadex [54] was observed by Suzuki et al. while the other two reports concluded that reversal time was unaffected in these inflammatory myopathies.

\section{Neuropathies (Table 4)}

A number of neuromuscular disorders could be grouped under neuropathies. One report on transverse myelitis and one report on multiple sclerosis were selected for this review (Table 4). Multiple sclerosis is a frequently occurring demyelinating neuropathy. The reports on multiple sclerosis patients did not suggest an altered dose of rocuronium or unusual response to sugammadex. However, a resistance to rocuronium was described by Staikou et al. manifesting as delay in onset of action following $1 \mathrm{mg} / \mathrm{kg}$ of rocuronium [55]. Transverse myelitis involves myelin destruction due to spinal cord inflammation. Prolonged paralysis was reported in a patient with transverse myelitis following the administration of $1.2 \mathrm{mg} / \mathrm{kg}$ rocuronium for rapid sequence induction [56].

\section{Motor neuron diseases (Table 5)}

Motor neuron diseases are a group of disorders characterized by progressive motor neuron degeneration, the most common of which is amyotrophic lateral sclerosis (ALS). It mainly involves lower motor neurons although in ALS both upper and lower motor neurons are affected [57]. In a patient with ALS reported by Kelsaka et al., clinical signs of inadequate recovery were observed despite a TOF ratio $>0.90$. Two minutes after sugammadex $2 \mathrm{mg} / \mathrm{kg}$ was administered, the patient recovered clinically and was extubated uneventfully [58] (Table 5). A similar discrepancy between TOF ratio and clinical signs of muscle strength recovery was also reported by Chang et al. $[59,60] .^{5}$ These authors henceforth questioned the reliability of TOF ratio to guide extubation in patients with this condition and proposed that this discordance may be related to the site and the severity of disease [59-61]. In fact, in patients reversed with sugammadex, a TOF ratio of 0.9 may not guarantee complete reversal without complete recovery of first twitch height (T1) [62]. Interestingly, no such issue was noticed by Yoo et al. in their patients with ALS or progressive muscle atrophy (PMA) in spite of their preexisting bulbar dysfunction. However, they had administered $5 \mathrm{mg} / \mathrm{kg}$ sugammadex as the pre-reversal TOF count was zero [63].

Use of sugammadex has also been investigated in patients with other motor neuron diseases (Table 5). Patients with spinobulbar muscular atrophy (Kennedy's disease) are at increased risk of laryngospasm and bulbar dysfunction and therefore aspiration [64]. Administration of sugammadex $2 \mathrm{mg} / \mathrm{kg}$ with TOF count of 1 has been reported to have resulted in $100 \%$ reversal within $180 \mathrm{~s}$ in a patient with Kennedy's disease [65]. Two papers reported the management of patients with spinal muscular atrophy $[13,66]$. Although an immediate and adequate response to sugammadex was observed in both these patients, an increased sensitivity and prolonged paralysis from rocuronium was reported by Vilela et al. [66].

Based on our literature search, the implications for the use of sugammadex can be found as endnotes.

\section{Other relevant considerations of sugammadex}

Use of sugammadex does not guarantee adequate recovery unless confirmed by TOFr of at least $0.9^{6}$. Since sugammadex does not form complexes with suxamethonium and benzylisoquinolinium muscle relaxants (mivacurium, atracurium and cisatracurium), it cannot be used to reverse these agents [67]. Further, factors such as age [68], cardiac output [69], increased stress due to surgery and pregnancy $[35,56]$ may contribute to delayed return of muscle power following sugammadex administration. . In

\footnotetext{
${ }^{5}$ Discordance between TOF ratios and clinical recovery have been reported in amyotrophic lateral sclerosis, which has been stated to be related to severity of disease and type of muscles involved.

${ }^{6}$ Quantitative neuromuscular monitor is essential in the management of these patients with a TOF ratio of $>0.9$ at peripheral muscles before extubation, to ensure adequate pharyngeal function and airway protection as well as to prevent complications such as atelectasis and pneumonia.

${ }^{7}$ Since delayed or failed recurarisation and long recovery times have been reported with adequately dosed sugammadex reversal even in normal surgical patients, presence of additional factors such as renal dysfunction, temperature fluctuation, acid-base or electrolyte imbalances in these patients or interaction with other medications (i.e. magnesium, baclofen,) necessitate prolonged post-operative observation, especially for respiratory insufficiency in patients with neuromuscular diseases.
} 


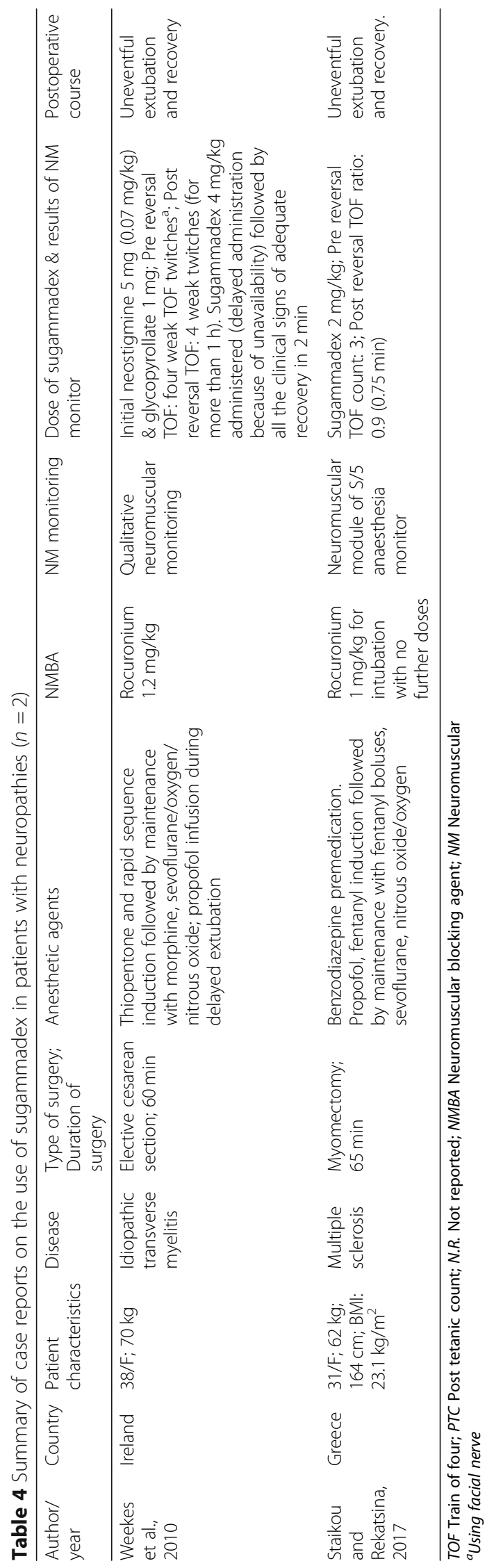




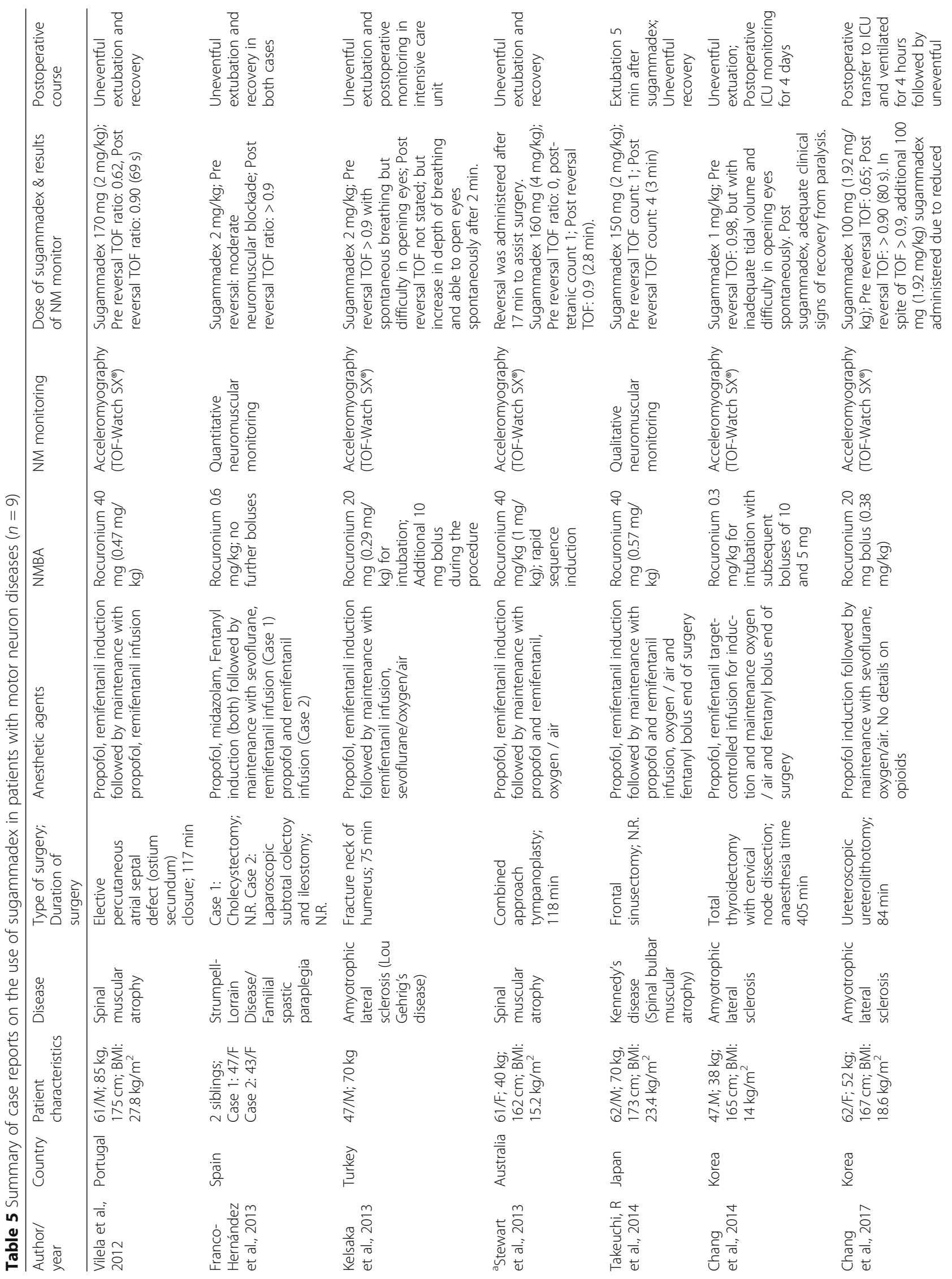


Gurunathan et al. BMC Anesthesiology

(2019) 19:213

Page 15 of 18

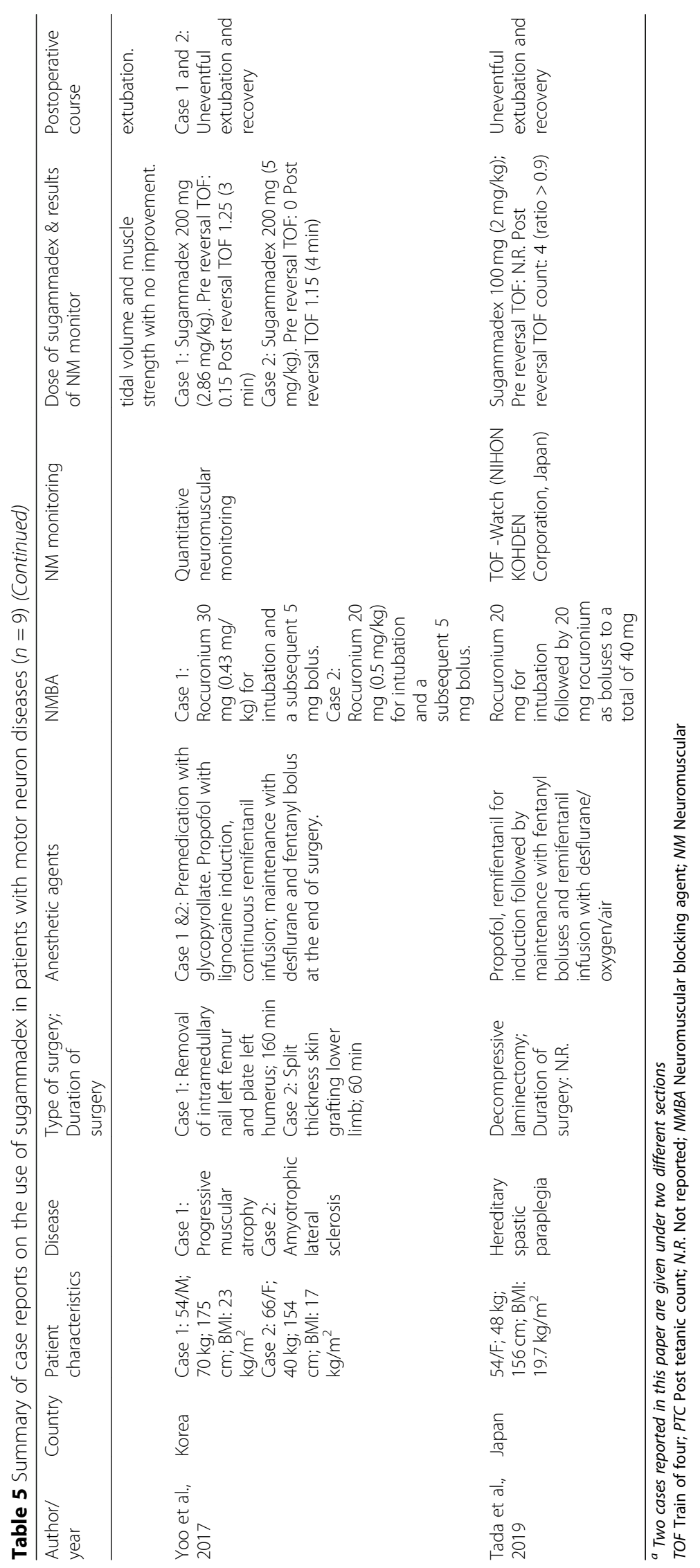


fact, even in routine surgical population, in spite of reversing with sugammadex, $2 \%$ of the patients were found to have residual paralysis $(\mathrm{TOF}<0.9)$ in the recovery room $[70]^{7}$. Fluctuations in muscle power may occur even after seemingly adequate reversal with sugammadex due to the redistribution of unbound muscle relaxant from the peripheral to the central compartment causing a rebound of blockade [71]. Despite the rapid reversal, there is no firm evidence to prove superiority of sugammadex over neostigmine in the prevention of postoperative pulmonary complications according to a recent review [72].

There have been reports of suspected hypersensitivity reactions to sugammadex $[73,74]$ but more evidence is needed in this regard to confirm its true incidence. In addition, there are concerns about displacement and capturing interactions with sugammadex. In particular, sugammadex may capture the prostagenic compound in oral contraceptive making it less effective [10]. Sugammadex is not also recommended for patients with severe renal impairment or those on dialysis [75] although evidence suggests that the complex with rocuronium can be removed by haemodialysis [76].

\section{Limitations of the review}

There are several limitations to this review. As this review summarizes the findings of various case reports, there are inherent drawbacks such as missing information, inability to draw inferences on causality and publication bias [77]. Non-English reports, abstracts without full texts and pediatric case reports are not included in this review. Since the primary goal of this article is to investigate the use of sugammadex patients in neuromuscular disorders and its clinical considerations, details on the disease severity and medications in every reported case were avoided. Since based on case reports, it has not been possible to provide conclusive evidence on the correct dose and timing of administration of sugammadex in patients with neuromuscular disorders.

\section{Conclusion}

Anesthetic management of patients with neuromuscular disorders is challenging due to the variability in the type, severity of the disorder and the extent of dysfunction in various muscle groups and their sensitivity to muscle relaxants in each patient.

Multiple case reports have been published describing the successful reversal of rocuronium with sugammadex in patients with neuromuscular disorders, however, there are also reports of adverse reactions and instances of inadequate reversal with administration of sugammadex. Currently, as there is limited knowledge on optimal dosing and timing of administration of sugammadex, a similar unpredictability in response also seem to occur with the use of sugammadex in this cohort of patients. Hence despite the advantages of sugammadex in this high-risk group of patients, it is strongly recommended to use quantitative neuromuscular monitoring to ensure complete recovery from the effects of steroidal muscle relaxants and to exercise extended postoperative supervision in these patients.

\section{Abbreviations}

ALS: Amyotrophic lateral sclerosis; APM: Adductor pollicis; CSM: Corrugator supercilii; MeSH: Medical Subject Headings; PM: Progressive muscular atrophy; PRISMA: Preferred reporting items for systematic reviews and metaanalyses; T1: First twitch

\section{Acknowledgements}

We would like to thank Mr. Chris Parker, librarian, The Prince Charles Hospital, Brisbane, Australia for his assistance with the literature search.

\section{Authors' contributions}

UG conceived this study. UG and LS performed the initial literature search of the databases. UG and SK screened the title and abstracts of all the articles from the literature search to select articles as well as extracted the data. LS was the third reviewer to resolve any disagreements between UG and SK. LS performed manual search of the reference list of the selected articles for additional articles. All the authors were involved in drafting the manuscript and approved the final version.

\section{Funding}

This research did not receive any specific grant from funding agencies in the public, commercial, or not-for-profit sectors.

\section{Availability of data and materials}

The datasets used and analyzed during the current study are available in the text.

Ethics approval and consent to participate

Not applicable.

\section{Consent for publication}

Not applicable.

\section{Competing interests}

U. G, S. K and L. S have been sponsored by Merck, Sharp \& Dohme (MSD) to participate in the MSD conferences.

Received: 27 August 2019 Accepted: 5 November 2019

Published online: 19 November 2019

References

1. Saez A, Acha B, Montero-Sanchez A, Rivas E, Escudero LM, Serrano C. Neuromuscular disease classification system. J Biomed Opt. 2013;18(6): 066017.

2. Hauck $L$, White C, Feasby TE, Zochodne DW, Svenson LW, Hill MD. Incidence of Guillain-Barre syndrome in Alberta, Canada: an administrative data study. J Neurol Neurosurg Psychiatry. 2008;79(3):318-20.

3. Breiner A, Widdifield J, Katzberg HD, Barnett C, Bril V, Tu K. Epidemiology of myasthenia gravis in Ontario, Canada. Neuromuscul Disord. 2016;26(1):41-6.

4. Carr AS, Cardwell CR, McCarron PO, McConville J. A systematic review of population based epidemiological studies in myasthenia gravis. BMC Neurol. 2010;10:46.

5. Naguib M. Sugammadex: another milestone in clinical neuromuscular pharmacology. Anesth Analg. 2007;104(3):575-81.

6. Bom A, Bradley M, Cameron K, Clark JK, Van Egmond J, Feilden H, MacLean EJ, Muir AW, Palin R, Rees DC, et al. A novel concept of reversing neuromuscular block: chemical encapsulation of rocuronium bromide by a cyclodextrin-based synthetic host. Angew Chem Int Ed Engl. 2002;41(2):266-70.

7. Srivastava A, Hunter JM. Reversal of neuromuscular block. Br J Anaesth. 2009;103(1):115-29.

8. Karalapillai D, Kaufman M, Weinberg L. Sugammadex. Crit Care Res. 2013; 15(1):57-62 
9. Abrishami A, Ho J, Wong J, Yin L, Chung F. Cochrane corner: sugammadex, a selective reversal medication for preventing postoperative residual neuromuscular blockade. Anesth Analg. 2010;110(4):1239.

10. Gold SJA, Harper NJN. The place of sugammadex in anaesthesia practice. Trends Anaesth Crit Care. 2012;2(1):4-9.

11. Stewart PA, Phillips $S$, de Boer HD. Residual neuromuscular blockade in myotonic dystrophy: lessons unlearned and sugammadex. Anaesth Intensive Care. 2011;39(4):756-7.

12. Petrun AM, Mekis D, Kamenik M. Successful use of rocuronium and sugammadex in a patient with myasthenia. Eur J Anaesthesiol. 2010; 27(10):917-8.

13. Stewart PA, Phillips S, De Boer HD. Sugammadex reversal of rocuroniuminduced neuromuscular blockade in two types of neuromuscular disorders: Myotonic dystrophy and spinal muscular atrophy. Rev Esp Anestesiol Reanim. 2013;60(4):226-9.

14. Racca F, Mongini T, Wolfler A, Vianello A, Cutrera R, Del Sorbo L, Capello EC, Gregoretti C, Massa R, De Luca D, et al. Recommendations for anesthesia and perioperative management of patients with neuromuscular disorders. Minerva Anestesiol. 2013;79(4):419-33

15. Madsen MV, Staehr-Rye AK, Gatke MR, Claudius C. Neuromuscular blockade for optimising surgical conditions during abdominal and gynaecological surgery: a systematic review. Acta Anaesthesiol Scand. 2015;59(1):1-16.

16. Dubois PE, Putz L, Jamart J, Marotta ML, Gourdin M, Donnez O. Deep neuromuscular block improves surgical conditions during laparoscopic hysterectomy: a randomised controlled trial. Eur J Anaesthesiol. 2014; 31(8):430-6.

17. Lee C. Goodbye suxamethonium! Anaesthesia. 2009;64(Suppl 1):73-81.

18. Durant NN, Katz RL. Suxamethonium. Br J Anaesth. 1982;54(2):195-208

19. Claudius C, Karacan H, Viby-Mogensen J. Prolonged residual paralysis after a single intubating dose of rocuronium. Br J Anaesth. 2007;99(4):514-7.

20. Shimauchi T, Yamaura K, Sugibe S, Hoka S. Usefulness of sugammadex in a patient with Becker muscular dystrophy and dilated cardiomyopathy. Acta Anaesthesiol Taiwanica. 2014;52(3):146-8.

21. Buzello W, Krieg N, Schlickewei A. Hazards of neostigmine in patients with neuromuscular disorders. Report of two cases. Br J Anaesth. 1982;54(5):529-34.

22. Ren WH, Jahr JS. Reversal of neuromuscular block with a selective relaxantbinding agent: sugammadex. Am J Ther. 2009;16(4):295-9.

23. Hristovska AM, Duch P, Allingstrup M, Afshari A. The comparative efficacy and safety of sugammadex and neostigmine in reversing neuromuscular blockade in adults. A Cochrane systematic review with meta-analysis and trial sequential analysis. Anaesthesia. 2018;73(5):631-41.

24. Wainwright AP, Brodrick PM. Suxamethonium in myasthenia gravis. Anaesthesia. 1987;42(9):950-7.

25. Eisenkraft JB, Book WJ, Papatestas AE. Sensitivity to vecuronium in myasthenia gravis: a dose-response study. Can J Anaesth. 1990;37(3):301-6.

26. Casarotti P, Mendola C, Cammarota G, Della Corte F. High-dose rocuronium for rapid-sequence induction and reversal with sugammadex in two myasthenic patients. Acta Anaesthesiol Scand. 2014;58(9):1154-8.

27. Blichfeldt-Lauridsen $L$, Hansen BD. Anesthesia and myasthenia gravis. Acta Anaesthesiol Scand. 2012;56(1):17-22.

28. Sungur Z, Senturk M. Anaesthesia for thymectomy in adult and juvenile myasthenic patients. Curr Opin Anaesthesiol. 2016;29(1):14-9.

29. De Boer HD, Van Egmond J, Driessen JJ, Booij LHJD. Sugammadex in patients with myasthenia gravis: correspondence. Anaesthesia. 2010;65(6):653.

30. Mouri $H$, Jo T, Matsui $H$, Fushimi $K$, Yasunaga $H$. Effect of Sugammadex on postoperative Myasthenic crisis in myasthenia gravis patients: propensity score analysis of a Japanese Nationwide database. Anesth Analg. 2019. https://doi.org/10.1213/ANE.0000000000004239. Epub ahead of print.

31. Sungur Ulke Z, Yavru A, Camci E, Ozkan B, Toker A, Senturk M. Rocuronium and sugammadex in patients with myasthenia gravis undergoing thymectomy. Acta Anaesthesiol Scand. 2013;57(6):745-8.

32. Garcia $V$, Diemunsch $P$, Boet $S$. Use of rocuronium and sugammadex for caesarean delivery in a patient with myasthenia gravis. Int J Obstet Anesth 2012;21(3):286-7.

33. Vymazal T, Krecmerova M, Bicek V, Lischke R. Feasibility of full and rapid neuromuscular blockade recovery with sugammadex in myasthenia gravis patients undergoing surgery - a series of 117 cases. Ther Clin Risk Manag. 2015;11:1593-6.

34. Kiss G, Lacour A, d'Hollander A. Fade of train-of-four ratio despite administration of more than $12 \mathrm{mg} \mathrm{kg}(-1)$ sugammadex in a myasthenia gravis patient receiving rocuronium. Br J Anaesth. 2013;110(5):854-5.
35. Sugi Y, Nitahara K, Shiroshita T, Higa K. Restoration of train-of-four ratio with neostigmine after insufficient recovery with Sugammadex in a patient with myasthenia gravis. A A Case Rep. 2013;1(3):43-5.

36. O'Leary RA, C MC. Stopped short: Sugammadex in undiagnosed Myasthenia gravis [Conference Abstract]. Eur J Anaesthesiol. 2013;30:26.

37. Iwasaki H, Takahoko K, Otomo S, Sasakawa T, Kunisawa T, Iwasaki H. Monitoring of neuromuscular blockade in one muscle group alone may not reflect recovery of total muscle function in patients with ocular myasthenia gravis. Can J Anaesth. 2013;60(12):1222-7.

38. Punnoose AR, Burke AE, Golub RM. JAMA patient page. Muscular dystrophy. JAMA. 2011;306(22):2526.

39. Matsumura T, Saito T, Yonemoto N, Nakamori M, Sugiura T, Nakamori A, Fujimura H, Sakoda S. Renal dysfunction can be a common complication in patients with myotonic dystrophy 1. J Neurol Sci. 2016;368:266-71.

40. Thiel RE. The myotonic response to suxamethonium. Br J Anaesth. 1967; 39(10):815-21.

41. Russell SH, Hirsch NP. Anaesthesia and myotonia. Br J Anaesth. 1994: 72(2):210-6.

42. Imison AR. Anaesthesia and myotonia--an Australian experience. Anaesth Intensive Care. 2001;29(1):34-7.

43. Wefki Abdelgawwad Shousha AA, Sanfilippo M, Sabba A, Pinchera P. Sugammadex and reversal of neuromuscular block in adult patient with duchenne muscular dystrophy. Case Rep Anesthesiol. 2014;2014:680568.

44. Baumgartner $P$, Baumgartner $P$. Rocuronium and sugammadex in myotonic dystrophy. Anaesth Intensive Care. 2010;38(5):959-60.

45. Matsuki Y, Hirose M, Tabata M, Nobukawa Y, Shigemi K. The use of sugammadex in a patient with myotonic dystrophy. Euro J Anaesth. 2011; 28(2):145-6

46. Mavridou P, Dimitriou V, Margaritis A, Manataki A. Anesthesia for laparoscopic surgery in a patient with myotonic dystrophy (Steinert's disease): beneficial use of sugammadex, but incorrect use of pethidine: a case report. Acta Anaesthesiol Belg. 2011;62(2):101-4.

47. Petrovski J. The use of sugammadex to reverse rocuronium in a patient with myotonic dystrophy. Anaesth Intensive Care. 2011:39(3):505-6.

48. Teixeira J, Matias B, Ferreira I, Taleço T, Duarte JS. Sugammadex is changing the paradigm in neuromuscular blockade in patients with myotonic dystrophy. J Perioper Pract. 2019;29(10):337-40.

49. Mangla C, Bais K, Yarmush J. Myotonic dystrophy and anesthetic challenges: a case report and review. Case Rep Anesthesiol. 2019;2019:4282305.

50. Kashiwai A, Suzuki T, Ogawa S. Sensitivity to rocuronium-induced neuromuscular block and reversibility with sugammadex in a patient with myotonic dystrophy. Case Rep Anesthesiol. 2012;2012:107952.

51. Stourac P, Krikava I, Seidlova J, Strazevska E, Huser M, Hruban L, Janku P, Gal R. Sugammadex in a parturient with myotonic dystrophy. Br J Anaesth. 2013;110(4):657-8.

52. Kosinova M, Stourac P, Harazim H, Janku P, Huser M, Vohanka S. Anaesthesia and orphan disease: rocuronium and sugammadex in the anaesthetic management of a parturient with Becker's myotonia congenita. Euro J Anaesthesiol. 2016:33(7):545-7.

53. Kendigelen P, Tutuncu AC, Ashyralyyeva G, Hamamcioglu EA, Kaya G. Sugammadex usage in a patient with dermatomyositis. J Clin Anesth. 2015; 27(5):438-9

54. Suzuki T, Nameki K, Shimizu H, Shimizu Y, Nakamura R, Ogawa S. Efficacy of rocuronium and sugammadex in a patient with dermatomyositis. $\mathrm{Br} \mathrm{J}$ Anaesth. 2012:108(4):703.

55. Staikou C, Rekatsina M. Use of rocuronium and sugammadex under neuromuscular transmission monitoring in a patient with multiple sclerosis. Saudi J Anaesth. 2017;11(4):472-5.

56. Weekes $\mathrm{G}$, Hayes N, Bowen M. Reversal of prolonged rocuronium neuromuscular blockade with sugammadex in an obstetric patient with transverse myelitis. Int J Obstet Anesth. 2010;19(3):333-6.

57. Tiryaki E, Horak HA. ALS and other motor neuron diseases. Continuum (Minneap Minn). 2014;20(5 Peripheral Nervous System Disorders):1185-207.

58. Kelsaka E, Karakaya D, Zengin EC. Use of sugammadex in a patient with amyotrophic lateral sclerosis. Med Princ Pract. 2013;22(3):304-6.

59. Chang YJ, Jung WS, Son WR, Jo YY. Discordance between train-of-four response and clinical symptoms in a patient with amyotrophic lateral sclerosis. Acta Med Okayama. 2014;68(2):125-7.

60. Chang TB, Huh J. Delayed neuromuscular recovery after use of sugammadex in a patient with amyotrophic lateral sclerosis: a case report. Anaesth Pain Intensive Care. 2017;21(4):475-8. 
61. Kelsaka E, Karakaya D, Zengin EC, Zengin EC. Use of sugammadex in a patient with amyotrophic lateral sclerosis. Med Principles Pract. 2013;22(3): 304-6.

62. Suzuki T. A train-of-four ratio of 0.9 may not certify adequate recovery after sugammadex. Acta Anaesthesiol Scand. 2011;55(3):368-9.

63. Yoo JH, Kim SI, Park SY, Jun MR, Kim YE, Kim HJ. Use of sugammadex in a patient with progressive muscular atrophy and in a patient with amyotrophic lateral sclerosis. Medicine (United States). 2017;96(23):e7098.

64. Sperfeld AD, Hanemann CO, Ludolph AC, Kassubek J. Laryngospasm: an underdiagnosed symptom of X-linked spinobulbar muscular atrophy. Neurology. 2005;64(4):753-4.

65. Takeuchi R, Hoshijima H, Doi K, Nagasaka H. The use of sugammadex in a patient with Kennedy's disease under general anesthesia. Saudi J Anaesth. 2014;8(3):418-20.

66. Vilela H, Santos J, Colaço J, Oliveira E, Canas-da-Silva P. Reversal of neuromuscular blockade with sugammadex in a patient with spinal muscular atrophy type III (Kugelberg-Welander syndrome). J Anesth. 2012; 26(2):306-7.

67. de Boer HD, van Egmond J, van de Pol F, Bom A, Booij LH. Sugammadex, a new reversal agent for neuromuscular block induced by rocuronium in the anaesthetized rhesus monkey. Br J Anaesth. 2006;96(4):473-9.

68. McDonagh DL, Benedict PE, Kovac AL, Drover DR, Brister NW, Morte JB, Monk TG. Efficacy, safety, and pharmacokinetics of sugammadex for the reversal of rocuronium-induced neuromuscular blockade in elderly patients. Anesthesiology. 2011;114(2):318-29.

69. Yoshida F, Suzuki T, Kashiwai A, Furuya T, Konishi J, Ogawa S. Correlation between cardiac output and reversibility of rocuronium-induced moderate neuromuscular block with sugammadex. Acta Anaesthesiol Scand. 2012; 56(1):83-7.

70. Cammu GV, Smet V, De Jongh K, Vandeput D. A prospective, observational study comparing postoperative residual curarisation and early adverse respiratory events in patients reversed with neostigmine or sugammadex or after apparent spontaneous recovery. Anaesth Intensive Care. 2012;40(6): 999-1006.

71. Eleveld DJ, Kuizenga K, Proost JH, Wierda JM. A temporary decrease in twitch response during reversal of rocuronium-induced muscle relaxation with a small dose of sugammadex. Anesth Analg. 2007:104(3):582-4

72. Hunter JM. Reversal of residual neuromuscular block: complications associated with perioperative management of muscle relaxation. $\mathrm{Br} J$ Anaesth. 2017;119(suppl_1):i53-62.

73. Menéndez-Ozcoidi L, Ortiz-Gómez JR, Olaguibel-Ribero JM, Salvador-Bravo MJ. Allergy to low dose sugammadex. Anaesthesia. 2011;66(3):217-219 213.

74. Takahiro T, Haruyama N, Mae T, Doi K, Ozaki M. Be careful about anaphylactic shock by antagonism of the neuromuscular blockade cases of anaphylactic shock induced by Sugammadex. Crit Care Med. 2012;40(12):291

75. Merck Sharp and Dohme (Australia) [www.medsafe.govt.nz/profs/datasheet/ b/briodionini.pdf].

76. Cammu G, Van Vlem B, van den Heuvel M, Stet L, el Galta R, Eloot S, Demeyer I. Dialysability of sugammadex and its complex with rocuronium in intensive care patients with severe renal impairment. Br J Anaesth. 2012 109(3):382-90.

77. Nissen T, Wynn R. The clinical case report: a review of its merits and limitations. BMC Res Notes. 2014;7:264.

\section{Publisher's Note}

Springer Nature remains neutral with regard to jurisdictional claims in published maps and institutional affiliations.

\section{Ready to submit your research? Choose BMC and benefit from:}

- fast, convenient online submission

- thorough peer review by experienced researchers in your field

- rapid publication on acceptance

- support for research data, including large and complex data types

- gold Open Access which fosters wider collaboration and increased citations

- maximum visibility for your research: over $100 \mathrm{M}$ website views per year

At $\mathrm{BMC}$, research is always in progress.

Learn more biomedcentral.com/submissions 